\title{
Study of the Reaction between Metals and Molten Salts (III) Electrical Conductivities of Silver- Molten Bismuth Trichloride Solutions
}

\author{
By Naoki Kamegashira*, Yoshiko Hama*, Masanobu Miyake* \\ and Tadao Sano*
}

\begin{abstract}
This study has been carried out to clarify the interactions between metals and molten salts. As one of a series of researches on mixtures of metals with molten salts, the electrical conductivity of salt-rich solutions of silver in molten bismuth trichloride has been measured. For this system, when silver is dissolved into molten bismuth trichloride, the following reaction is considered :

$3 \mathrm{Ag}+\mathrm{BiCl}_{3}=3 \mathrm{AgCl}+\mathrm{Bi}$.

Bismuth thus produced, however, dissolves into molten bismuth trichloride as has been well known. The solution, therefore, is considered to be a mixture of silver chloride and bismuth-bismuth trichloride. For the region ranging from pure salt to $30 \mathrm{~mol} \% \mathrm{Ag}$ content, the electrical conductivity was measured by means of the capillary cell method with an alternating current in the temperature range $250^{\circ} \sim 400^{\circ} \mathrm{C}$ under argon atmosphere. The electrical conductivity increased almost linearly with increasing $\mathrm{Ag}$ content in every temperature range. It has been shown that below $13.5 \mathrm{~mol} \% \mathrm{Ag}$ and at temperatures lower than $350^{\circ} \mathrm{C}$ the ionic conductance is predominant, but in a range of above $13.5 \mathrm{~mol} \% \mathrm{Ag}$ and temperatures higher than $350^{\circ} \mathrm{C}$ the semiconducting mechanism becomes predominant which can be explained by the electron hopping model.

(Received February 7, 1967)
\end{abstract}

\section{Introduction}

Little has been known about properties of mixtures of metals and molten salts of other metals ${ }^{(1)}$ because of the complexity of their reaction processes. For example, a metal is formed from a solvent reduced by solute metal, in which case the metal dissolves into the remaining salts and eventually dissolves in other molten halides in the salt-rich region. In previous reports the present authors described the experimental results on the dissolution of $\mathrm{Cu}$ into molten $\mathrm{BiCl}_{3}{ }^{(2)}$ and the electrical conductivities of solutions of the tin-molten bismuth trichloride system ${ }^{(3)}$.

Subsequent work has been carried out on mixtures of metals and molten salts of other metals, and the results of electrical conductivity measurements in the $\mathrm{Ag}-\mathrm{BiCl}_{3}$ system up to $400^{\circ} \mathrm{C}$ are reported here. The specific conductivity of the solutions of this system increases with metal content and there is no composition range where the specific conductivity decreases or shows a maximum value as in the case of the bismuth-molten bismuth trichloride system or the tinmolten bismuth trichloride system.

In the bismuth-bismuth halides system, especially iodide and bromide, an electron hopping model ${ }^{(4) \sim(6)}$ has been proposed for elucidation of the mechanism of electrical conduction and the applicability of this

* Department of Nuclear Engineering, Faculty of Engineering, Osaka University, Osaka, Japan.

(1) M. A. Bredig : Molten Salt Chemistry ed. by M.Blander, Interscience Publishers, (1964), p. 367.

(2) N. Kamegashira, Y. Hama, S. Imoto and T.Sano : Trans. JIM, 7(1966), 67 .

(3) N. Kamegashira, Y. Hama and T. Sano: Trans. JIM, 7 (1966), 244.

(4) L. F. Grantham and S. J. Yosim : J. Chem. Phys., 38 (1963), 1671.

(5) D. O. Raleigh: J. Chem. Phys., 38 (1963), 1677.

(6) L. F. Grantham: J. Chem. Phys., 43 (1965), 1415.

Trans.J I M model has been inferred for the chloride system. In these systems the reduced bismuth species has been considered to be a monovalent ion and the monovalent cation contributes to the predominant mechanism of electrical conduction. It has been made clear that when silver dissolves into molten bismuth trichloride, the electrical conduction in the solutions can be well explained by the electron exchange model in a range of higher metal contents and temperatures even for the chloride system. This is greatly different from the case of the $\mathrm{Sn}-\mathrm{BiCl}_{3}$ system ${ }^{(2)}$ where the ionic conduction is predominant and the electron exchange model is not applicable.

\section{Experimental}

The capillary cell method previously described ${ }^{(2)}$ was again used, and the alternating current conductivity was measured with the Yokogawa Universal Bridge. The cell constants of the conductance cell used in this experiment were about $150 \sim 285 \mathrm{~cm}^{-1}$ which were calibrated with a standard $\mathrm{KCl}$ solution ${ }^{(7)}$. The conductivity measurement was made in the temperature range of $250^{\circ} \sim 400^{\circ} \mathrm{C}$ under argon atmosphere. The reproducibility of the results was within $1.5 \%$. The preparation of the salts before experiment has also been mentioned elsewhere ${ }^{(1)}$. The silver used was $99.99 \%$ in purity (supplied by Yamamori Noble Metal Co. Ltd.).

Compositions of the solutions were determined by chemical analysis after each experiment. The volumetric analysis was employed for silver. The procedure of chemical analysis is as follows: The samples were pulverized and weighed after drying. Hydrochloric acid was added to make silver precipitate as silver

(7) Y.Yamaguchi : Kiso Denki Kagaku, Shokabo, (1959), p. 18 (Japanese) 
chloride. After filtration the precipitates were burned in a crucible and then dissolved in nitric acid to form silver nitrate. This silver was titrated with potassium thiocyanate, according to the Volhard method, using ferric ammonium sulfate an an indicator.

\section{Experimental Results and Discussion}

For the silver and bismuth trichloride system, a phase diagram has been proposed by Sokolowa ${ }^{(8)}$; that is, below 10 at $\% \mathrm{Ag}$ there is a monophase, i.e. a saltrich phase containing $\mathrm{Ag}$, and when the Ag-content exceeds 10 at $\%$, a metallic bismuth phase appears. It can be considered that the following reaction occurs when silver dissolves into molten bismuth trichloride :

$$
3 \mathrm{Ag}+\mathrm{BiCl}_{3}=3 \mathrm{AgCl}+\mathrm{Bi} \text {. }
$$

But metallic Bi has not been found in the region of less than 10 at $\% \mathrm{Ag}$, according to its diagram. In the range below this composition Ag dissolves into molten $\mathrm{BiCl}_{3}$. The electrical conductivity was measured for the solution of this monophase region in the temperature range $250^{\circ} \sim 400^{\circ} \mathrm{C}$.

The values of specific conductivity of the $\mathrm{Ag}-\mathrm{BiCl}_{3}$ solution are given in Table 1 , in which the composi-

Table 1 Specific conductivities of $\mathrm{Ag}-\mathrm{BiCl}_{3}$ solutions.

\begin{tabular}{|c|c|c|c|c|c|c|c|}
\hline $\mathrm{mol} \% \mathrm{Ag}$ & $t^{\circ} \mathrm{C}$ & $\kappa$ & $\Delta$ & $\mathrm{mol} \% \mathrm{Ag}$ & $t^{\circ} \mathrm{C}$ & $\kappa$ & $\Delta$ \\
\hline \multirow[t]{2}{*}{0} & \multirow{2}{*}{$\begin{array}{l}250 \\
275 \\
300 \\
325 \\
350 \\
375 \\
400\end{array}$} & \multirow{2}{*}{$\begin{array}{l}0.371 \\
0.423 \\
0.467 \\
0.496 \\
0.530 \\
0.553 \\
0.563\end{array}$} & \multirow[t]{2}{*}{$\begin{array}{l}0.052 \\
0.044 \\
0.029 \\
0.034 \\
0.023 \\
0.010\end{array}$} & 13.50 & $\begin{array}{l}349 \\
372 \\
397\end{array}$ & $\begin{array}{l}0.655 \\
0.705 \\
0.753\end{array}$ & $\begin{array}{l}0.050 \\
0.048\end{array}$ \\
\hline & & & & \multirow[t]{2}{*}{16.48} & \multirow{2}{*}{$\begin{array}{l}253 \\
279 \\
304 \\
327 \\
355 \\
374 \\
391\end{array}$} & \multirow{2}{*}{$\begin{array}{l}0.450 \\
0.512 \\
0.580 \\
0.636 \\
0.705 \\
0.760 \\
0.815\end{array}$} & \multirow{2}{*}{$\begin{array}{l}0.062 \\
0.068 \\
0.056 \\
0.069 \\
0.055 \\
0.055\end{array}$} \\
\hline \multirow[t]{2}{*}{1.22} & \multirow{2}{*}{$\begin{array}{l}250 \\
273 \\
298 \\
317 \\
343 \\
367 \\
396\end{array}$} & \multirow{2}{*}{$\begin{array}{l}0.381 \\
0.434 \\
0.473 \\
0.499 \\
0.540 \\
0.574 \\
0.598\end{array}$} & \multirow[t]{2}{*}{$\begin{array}{l}0.053 \\
0.039 \\
0.026 \\
0.041 \\
0.026 \\
0.024\end{array}$} & & & & \\
\hline & & & & \multirow[t]{2}{*}{22.43} & \multirow{2}{*}{$\begin{array}{l}252 \\
273 \\
299 \\
328 \\
353 \\
375 \\
398\end{array}$} & \multirow{2}{*}{$\begin{array}{l}0.460 \\
0.533 \\
0.619 \\
0.670 \\
0.755 \\
0.827 \\
0.899\end{array}$} & \multirow{2}{*}{$\begin{array}{l}0.073 \\
0.086 \\
0.051 \\
0.085 \\
0.072 \\
0.072\end{array}$} \\
\hline \multirow[t]{2}{*}{6.65} & \multirow{2}{*}{$\begin{array}{l}250 \\
278 \\
307 \\
332 \\
356 \\
376 \\
393\end{array}$} & \multirow{2}{*}{$\begin{array}{l}0.399 \\
0.459 \\
0.513 \\
0.549 \\
0.585 \\
0.615 \\
0.654\end{array}$} & \multirow[t]{2}{*}{$\begin{array}{l}0.060 \\
0.054 \\
0.036 \\
0.036 \\
0.030 \\
0.039\end{array}$} & & & & \\
\hline & & & & \multirow[t]{2}{*}{28.36} & \multirow{2}{*}{$\begin{array}{l}252 \\
280 \\
306 \\
325 \\
353 \\
373 \\
390\end{array}$} & $\begin{array}{l}0.472 \\
0.530\end{array}$ & \multirow{2}{*}{$\begin{array}{l}0.058 \\
0.091 \\
0.059 \\
0.141 \\
0.109 \\
0.069\end{array}$} \\
\hline 13.50 & $\begin{array}{l}253 \\
278 \\
298 \\
327\end{array}$ & $\begin{array}{l}0.424 \\
0.485 \\
0.545 \\
0.605\end{array}$ & $\begin{array}{l}0.061 \\
0.060 \\
0.060 \\
0.050\end{array}$ & & & $\begin{array}{l}0.680 \\
0.821 \\
0.930 \\
1.009\end{array}$ & \\
\hline
\end{tabular}

tion is expressed in mol percent metal and each metal is regarded as monatomic. The forth column $(\Delta)$ in Table 1 shows an increment in specific conductivity at intervals of $25^{\circ} \mathrm{C}$ (i.e., the temperature coefficient of $k$ at intervals of $25^{\circ} \mathrm{C}$ ). The change in specific conductivity of the $\mathrm{Ag}-\mathrm{BiCl}_{3}$ solution is shown in Fig. 1 as a function of composition over the various temperature ranges. As shown in this figure, the specific

(8) M. A. Sokolowa : quoted from "Electrochemistry of Molten Salt" by U. K. Delimarskii and B. F. Markow, Mosow, (1960), p. 231 (Russian) conductivity increases almost linearly with Ag content in each temperature range. Moreover, the slope increases as the temperature increases. In the lower temperature range, therefore, the curves are nearly convex, while in the higher temperature range they

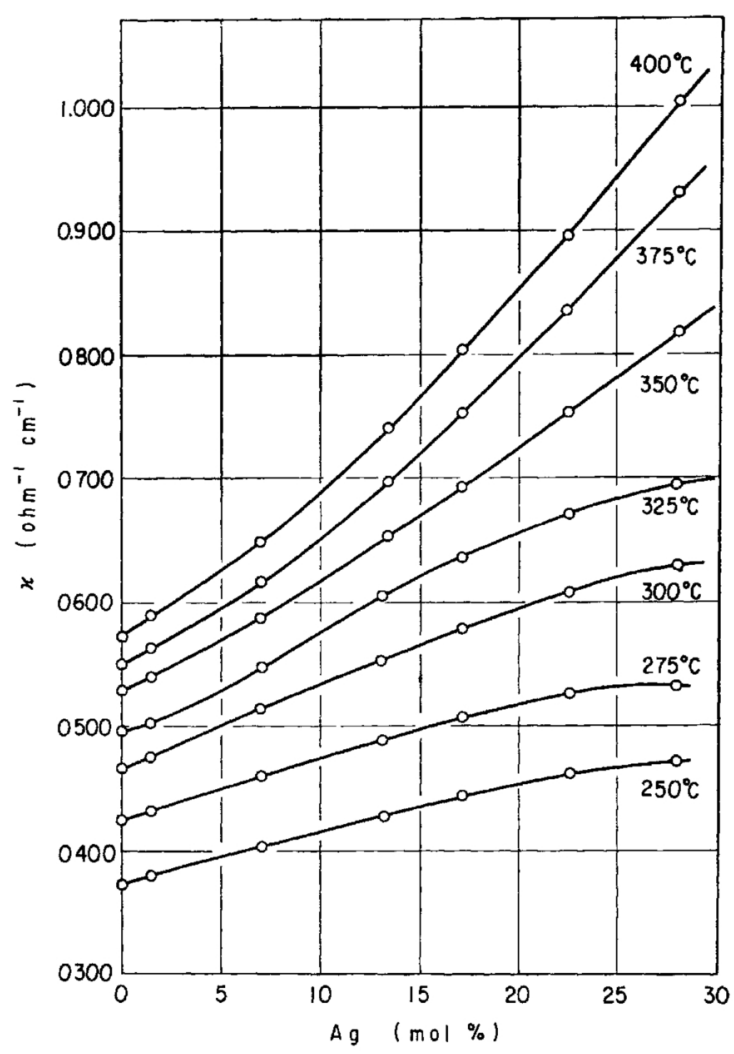

Fig. 1 Specific conductivity vs mole percent metal in the $\mathrm{Ag}-\mathrm{BiCl}_{3}$ systems at $250^{\circ}, 275^{\circ}, 300^{\circ}$, $325^{\circ}, 350^{\circ}, 375^{\circ}, 400^{\circ} \mathrm{C}$.

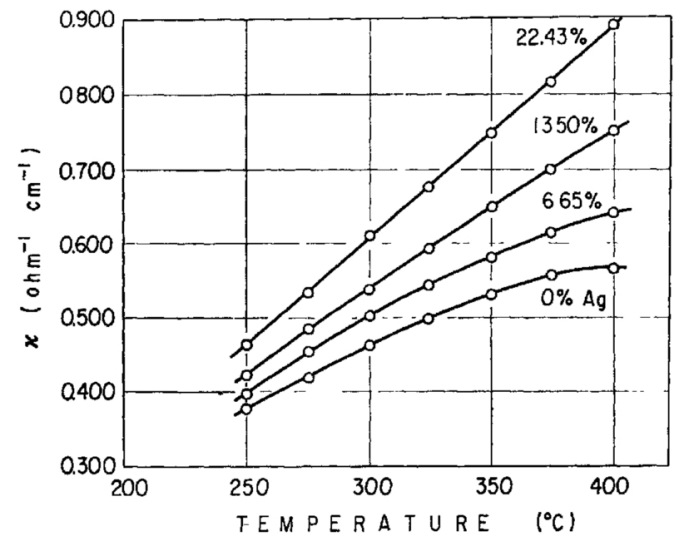

Fig. 2 Specific conductivity vs temperature in the $\mathrm{Ag}-\mathrm{BiCl}_{3}$ system.

become reversely concave.

The specific conductivity is plotted in Fig. 2 as a function of temperature for vảrious compositions. In the case of pure $\mathrm{BiCl}_{3}$ the temperature coefficient is large at lower temperatures and decreases at higher temperatures, showing a bending toward the pure temperature $\operatorname{axis}^{(9)}$. However, with the addition of metal, the temperature coefficient becomes almost constant and the curves become nearly linear, with the

(9) A. H. W. Aten : Z. Phys. Chem., 66 (1909), 641. 
gradient which becomes steeper as the metal content increases. It can be seen from Fig. 2 that the higher the metal content, the larger the conductivity of this system, and this relation is also found in the Sn-molten $\mathrm{BiCl}_{3}$ system, but a reversed relation is found in the $\mathrm{Bi}-$ molten $\mathrm{BiCl}_{3}$ system.

The logarithm of the specific conductivity is plotted in Fig. 3 against the reciprocal of absolute temperatures in the salt-rich region of the $\mathrm{Ag}-\mathrm{BiCl}_{3}$ system.

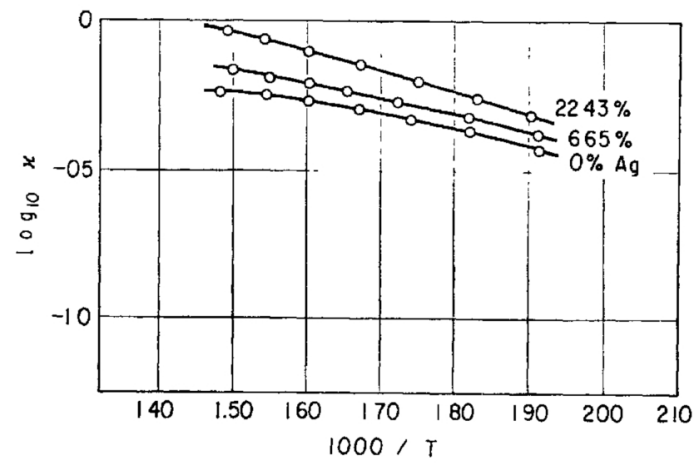

Fig. $3 \log _{10}$ (specific conductivity of $\mathrm{Ag}-\mathrm{BiCl}_{3}$ solutions) vs reciprocal of temperature at various mole percent Ag compositions.

In this case, a positive temperature coefficient which is characteristic of both ionic and semiconducting melts was also shown as in the case of the $\mathrm{Sn}-\mathrm{BiCl}_{3}$ system. This relation between the logarithm of specific conductivity and the reciprocal of temperature in the $\mathrm{Ag}-\mathrm{BiCl}_{3}$ system becomes linear with increasing content, as is observed in the $\mathrm{Sn}-\mathrm{BiCl}_{3}$ system. The activation energies for electrical conduction can be calculated from Fig. 3 . The change in the activation energy against the concentration of silver is plotted in Fig. 4, where the value of activation energy gradually increases with metal content and is almost equal to those in other metals-molten helides systems ${ }^{(10)}$.

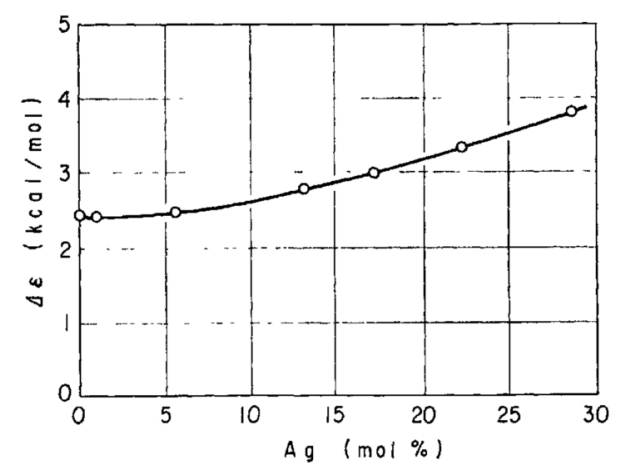

Fig. 4 Activation energy vs mole percent meta] in the $\mathrm{Ag}-\mathrm{BiCl}_{3}$ system.

In Fig. 5 the logarithms of specific conductivity of the $\mathrm{Ag}-\mathrm{BiCl}_{3}$ system are plotted as a function of solution composition at intervals of $75^{\circ} \mathrm{C}$. The exponential dependence of conductivity on composition is observed in the salt-rich region of the $\mathrm{Bi}-\mathrm{BiX}_{3}$ system. While this exponential dependence is found

(10) G. W. Mellors and S. Senderoff : J. Phys. Chem., 64 (1960), 294. in the range of higher metal contents and temperatures in the $\mathrm{Bi}-\mathrm{BiX}_{3}$ system, it is seen that the exponential dependence occurs even in the low metal content range at all temperatures. Moreover, the slope of this straight line increases with increasing temperature.

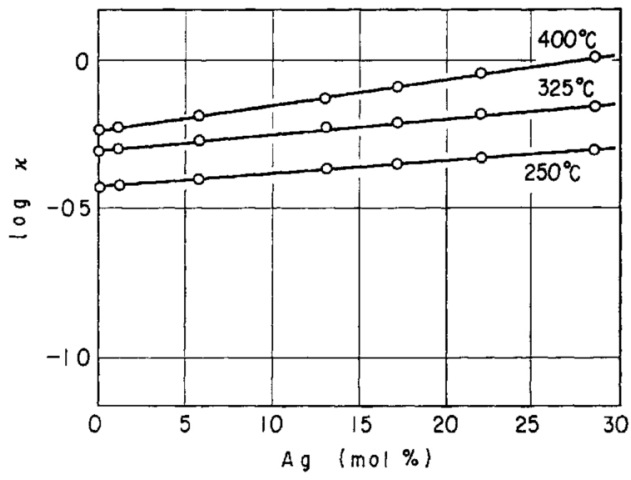

Fig. $5 \log _{10}$ (specific conductivity of the $\mathrm{Ag}-\mathrm{BiCl}_{3}$ system) vs mole percent metal compasition at intervals of $75^{\circ} \mathrm{C}$.

If the composition of silver is $C \mathrm{~mol} \%$, it is found from Fig. 5 that the specific conductivity, $\kappa$, is related to the Ag-content by

$$
K=A \exp (b C),
$$

where $A$ and $b$ are constants and $b$ is strongly dependent on temperature as shown in Fig. 6.

For elucidation of the linear relationship between $\log \kappa$ and mol per cent, it is convenient to use the molar conductance instead of the specific conductivity. The molar conductance is a product of specific conductivity and molar volume. That is,

$$
\Lambda=\kappa V \text {, }
$$

where $V$ is the molar volume and is defined on the basis of the concentrations of metal and salt. Thus,

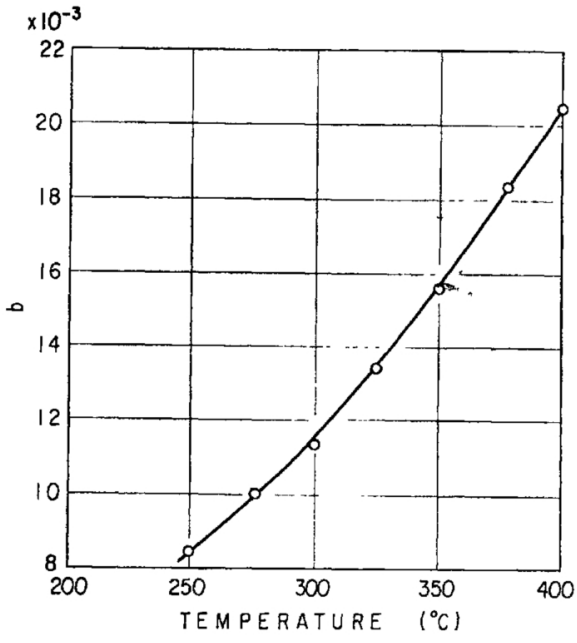

Fig. 6 The coefficient $b$ vs temperature.

$$
V=\left(M_{m} X_{m}+M_{s} X_{s}\right) / \rho,
$$

where $M$ is the molecular weight, $X$ is the mole fraction, $m$ and $s$ are silver and bismuth trichloride, respectively, and $\rho$ is the density of the solution. For lack of the available data on the density in this system, 
it is assumed that $\rho$ is equal to the density of pure salt. Of course, the density of the solution would increase as the metal content increases, but in the salt-rich region this assumption is probably reasonable because the the present study dealt with only the region of less than 10 at $\%$ metal contents.

According to Grantham, the excess molar conductance, $A_{\text {ex }}$, which is the molar conductance of the solution after subtraction of the ionic contribution of $\mathrm{BiCl}_{3}, \Lambda_{\text {salt }}$, is given by ${ }^{(6)}$

$$
\Lambda_{\mathrm{ex}}=\Lambda-\Lambda_{\mathrm{salt}}
$$

where the ionic contribution is assumed to be relatively constant in the composition ranges investigated. This excess molar conductance would be useful as a measure, excepting the cases of ionic conduction. In the present experiment the temperature coefficients of conductivity were positive for all the regions and no metallic conduction was observed. However, from the large increase in conductivity with metal content (e.g., Fig. 1) and the exponential dependence of conductivity on the concentration of metal, a mechanism by the electron exchange between two cations can be proposed. Such a mechnism has heretofore been proposed to explain results on the conductivity of $\mathrm{Bi}-\mathrm{BiI}_{3}{ }^{(5)}, \mathrm{Bi}-\mathrm{BiBr}_{3}$ and $\mathrm{Bi}-\mathrm{BiCl}_{3}{ }^{(6)}$ systems or in some other solutions.

When silver dissolves in molten bismuth trichloride, silver enters into the solution as a monovalent ion and the trivalent bismuth ion is reduced to a lower valent ion. In the $\mathrm{Bi}-\mathrm{BiX}{ }_{3}$ system this lower valent ion is identified as monovalent, but in the $\mathrm{Ag}-\mathrm{BiCl}_{3}$ system there are no magnetic susceptibility data and the ionic species contained in the solution are unknown. However, the solution becomes a mixture of silver chloride and bismuth-rich bismuth trichloride solution when silver dissolves into molten bismuth trichloride (the free energy of formation $-\Delta G$, is 23.6 kcal for $\mathrm{AgCl}$ and $22.7 \mathrm{kcal}$ for $\mathrm{BiCl}_{3}$ per one $\mathrm{Cl}$ atom at $500^{\circ} \mathrm{K}$, respectively), and the species of bismuth ions will be considered to be trivalent and monovalent, between which the electron exchange will occur.

By the electron transfer model the electronic conductivity is essentially a function of the average distance between adjacent cation pairs, $R$, which is defined as

$$
R=(V / N)^{1 / 3}
$$

where $N$ is Avogadro's number. Fig. 7 shows a typical plot of the $\log \Lambda_{\mathrm{ex}}$ as a function of $R$ at several temperatures for the $\mathrm{Ag}-\mathrm{BiCl}_{3}$ system. In the range of $R$ values, lower than $5.0 \AA$ (more than $13.50 \mathrm{~mol} \%$ Ag content trand temperatures higher than $350^{\circ} \mathrm{C}, \Lambda_{\text {ex }}$ for the $\mathrm{Ag}-\mathrm{BiCl}_{3}$ system appears to be an exponential function of $R$ in agreement with the electron transfer model. Namely it is found that when $\mathrm{Ag}$ dissolves into molten $\mathrm{BiCl}_{3}$, the electron transfer is easy to appear even in the chloride system. In the range of $R$ values larger than $5.0 \AA$ (lower than $13.50 \mathrm{~mol} \%$ Ag content) the deviation from linearity occurs because in these dilute solutions the ionic conductivity becomes predominant and Eq. (5) are no longer applicable. The same thing is true in the range of lower temperatures, where many polymers such as $\mathrm{Bi}_{4} \mathrm{Cl}_{4}$ species are present and consequently the conduction through these species are substantially large.

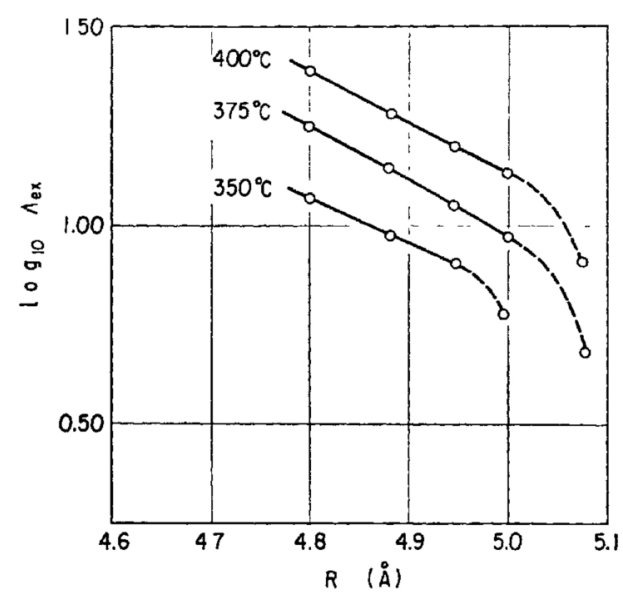

Fig. $7 \log _{10}$ (the excess molar conductivity vs the average distance between exchanging sites in the silver-bismuth trichloride systems.

It has been reported that the excess molar conductivity may be related to the jump frequency $\nu$ by ${ }^{(6)}$

$$
\nu=\left(k T \Lambda_{\mathrm{ex}}\right) /\left(N X_{m} e^{2} R^{2}\right),
$$

where $k$ is the Boltzmann constant and $e$ is the electronic charge. Fig 8 shows curves of $\log \nu$ vs reciprocal of absolute temperature. In the range of

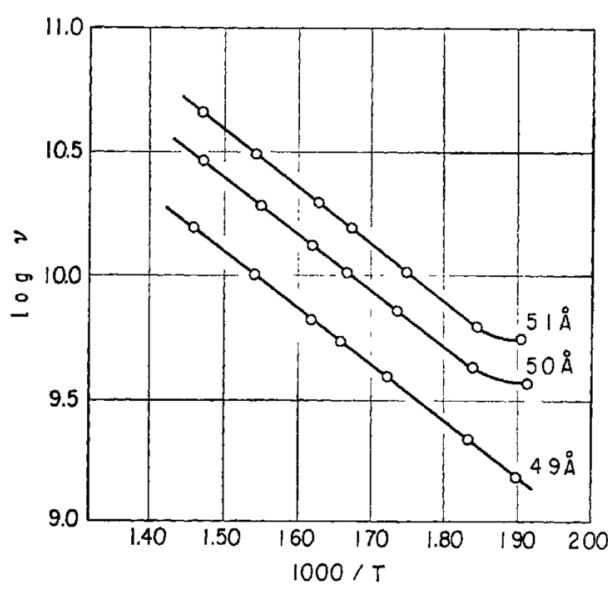

Fig. $8 \log _{10}$ (the calculated exchange frequency) vs reciprocal of temperature at a constant distance between neighbouring cations.

below $R=5.0 \AA$ and above $350^{\circ} \mathrm{C}$, it is seen that the $\log \nu$ is linearly dependent on $1 / T$ at constant $R$, suggesting the applicability of the electron transfer model to the $\mathrm{Ag}-\mathrm{BiCl}_{3}$ system. From the slope of these lines in Fig. 8 the height of the energy barrier can be calculated to be $11.5 \mathrm{kcal} / \mathrm{mol}$, which is a little smaller than the bond energy of $\mathrm{Bi}-\mathrm{Cl}$. In the $\mathrm{Bi}-\mathrm{BiCl}_{3}$ system the applicability of electron hopping model is restricted to some extent because of the limited solubility, but when Ag dissolves into molten $\mathrm{BiCl}_{3}$, it seems that this model can be applied even in the chloride system. 


\section{Summary}

Investigations have been made on the interactions between the silver and molten bismuth trichloride systems. The electrical conductivities were measured by the alternating current method with a capillary cell and the results obtained are as follows :

(1) The specific conductivity in the $\mathrm{Ag}-\mathrm{BiCl}_{3}$ system increases almost linearly with increasing $\mathrm{Ag}$-content and the higher the temperature, the larger the slope.

(2) The specific conductivity exponentially depends on the concentration of metal.

(3) The lowering of the specific conductivity as in the $\mathrm{Sn}-\mathrm{BiCl}_{3}$ system was not observed in the $\mathrm{Ag}-\mathrm{BiCl}_{3}$ system. This indicates the absence of complexes in the $\mathrm{Ag}-\mathrm{BiCl}_{3}$ system, which makes electrons move easily from one cation site to the other.

(4) These behaviors have been explained by the electron hopping model in the ranges of higher metal contents and temperatures.

(5) In the ranges of lower metal contents and temperatures the ionic conductance is predominant.

\section{Acknowledgment}

The authors wish to express their sincere thanks to the Yamamori Noble Metal Co. Ltd. for kindly furnishing the samples. 